ARTÍCULO ORIGINAL

\title{
Papel de la resonancia magnética fetal en la valoración de las anomalías prenatales
}

\section{Role of fetal magnetic resonance in the evaluation of prenatal anomalies}

Carla Ma García-Moreno1*, Eduardo Torres-Olivas', María Barrera-Esparza1, Nancy Sierra-Lozada², Manuel Casillas-Barrera², Jana A. López-Félix², Ma Teresita Leis-Márquez² y Sandra Acevedo-Gallegos ${ }^{3}$

${ }^{1}$ Departamento de Resonancia Magnética, Hospital Ángeles Lomas, Estado de México; ${ }^{2}$ Clínica Materno Fetal, Hospital Ángeles Lomas, Estado de México; ${ }^{3}$ Clínica Materno Fetal, Instituto Nacional de Perinatología, Ciudad de México, México

\section{RESUMEN}

Objetivo: Valorar la contribución de la resonancia magnética fetal (RMF) como estudio complementario del diagnóstico prenatal. Material y métodos: Se compararon los hallazgos obtenidos por US fetal de 146 pacientes con los obtenidos por medio de RMF. Los pacientes se dividieron en dos grupos: mujeres con 18 a 27 semanas de gestación (SDG) y mujeres con 28 a 36 SDG. Se consideró como aporte de información adicional de la RMF cuando ésta confirmó los hallazgos de US y suministró información adicional, cambió el diagnóstico de US y produjo un nuevo diagnóstico, o descartó el diagnóstico del US y estableció el estudio como normal. Cuando el estudio de RMF sólo confirmó los hallazgos de US no se consideró aportación de información adicional. Resultados: En el 56\% de los casos, la RMF aportó información adicional. En el 44\% sólo confirmó los hallazgos observados en el US. No hubo diferencia entre los dos grupos de 18 a 27 y 28 a 36 SDG. Conclusión: La RMF constituye una herramienta valiosa para la valoración de patología prenatal, ya que en el 56\% de los casos proporciona información adicional a la obtenida por US.

Palabras clave: Resonancia magnética fetal. Ultrasonido prenatal. Diagnóstico prenatal. 


\section{ABSTRACT}

Objective: To evaluate the contribution of fetal magnetic resonance (FMR) as a complementary study in prenatal diagnosis of prenatal pathology. Material and methods: We compared the ultrasound (US) findings of 146 patients with the Fetal MRI findings. Patients were divided in two groups as follows: Patients with 18 to 27 weeks of gestation and patients with 28 to 36 weeks of gestation. FMR diagnostic contribution was considered when it: Confirmed de US diagnosis and added new information, when it changed the US diagnosis for a new one or when it ruled out the US findings and found no alterations. FMR non-contribution was considered when the FMR just confirmed the US findings without adding any new information. Results: FMR contributed with additional information in $56 \%$ of cases. In $44 \%$ of cases it just confirmed the ultrasonographic findings. There was no difference between the groups of 18-27 weeks and 28-36 weeks. Conclusion: The FMR is a valuable tool for the evaluation of prenatal pathology, contributing with additional information to that obtained by ultrasound in $56 \%$ of the cases.

Key words: Fetal magnetic resonance imaging. Prenatal ultrasound. Prenatal diagnosis.

\section{INTRODUCCIÓN}

El diagnóstico prenatal aporta información acerca del pronóstico para la vida y función del feto y el recién nacido. El ultrasonido fetal es la modalidad de imagen principal y norma de referencia para la detección de enfermedad prenatal ${ }^{1,2}$. Sin embargo, en ocasiones suministra datos insuficientes o inespecíficos y genera dudas diagnósticas o incertidumbre en el médico y los padres. En estos casos, las publicaciones médicas actuales proponen $\mathrm{y}$ recomiendan el uso de la resonancia magnética fetal $(\mathrm{RMF})^{3}$.

La RMF se ha utilizado desde 1983 como un estudio complementario para el diagnóstico de la enfermedad prenatal. En comparación con el ultrasonido, la RMF no está limitada en grado significativo por la obesidad materna, posición fetal u oligohidramnios ${ }^{4}$.
La RMF es un método diagnóstico no invasivo que no emite radiación ionizante y hasta la fecha no se han notificado efectos secundarios negativos o secuelas tardías a partir del segundo trimestre, por lo que se considera un método seguro desde esa edad gestacional. No se recomienda la RMF antes de la SDG 18 debido a las limitaciones de tamaño y movimiento fetal ${ }^{5,6}$.

Las indicaciones para la RMF incluyen la confirmación de hallazgos ultrasonográficos no concluyentes y la valoración de diagnósticos ecográficamente inadvertidos. Aunque la indicación más común para RMF es la afección del SNC, la RMF puede utilizarse para el diagnóstico de distintos sistemas y aparatos del organismo fetal.

Tanto el Colegio Americano de Radiología (ACR) como la Sociedad de Radiología Pediátrica (SPR) y la Sociedad Internacional de 
Ultrasonido para Ginecología y Obstetricia (ISUGO) tienen en sus guías de práctica radiológica indicaciones para la RMF en la patología prenatal ${ }^{7-10}$.

Otro uso de la RMF que ha cobrado auge en años recientes es su utilización en la planeación quirúrgica in utero, en los casos con un defecto por ultrasonido diagnosticado y en los que se requiere más información para determinar el tamaño, la localización y la relación con otras estructuras para planear la reparación por medios quirúrgicos fetales ${ }^{11}$.

Las secuencias más empleadas en RMF son eco de espín rápidas de disparo único (SSFSE, single shot fast spin echo), que tienen nombres y acrónimos distintos según sea el fabricante (T2-SSH-TSE en Philips, T2-SSFSE en General Electric y HASTE en Siemens). Por lo general, las secuencias T1 se adquieren mediante ecos de gradiente bidimensional y son útiles para la detección de productos hemáticos, calcificaciones, grasa y meconio, así como la valoración de órganos hiperintensos en secuencias ponderadas en T1, como la glándula tiroides y el hígado. Las secuencias de difusión son en particular útiles en la valoración de hemorragias, tumores, lesiones isquémicas y parénquima renal normal. En algunos estudios clínicos también se han usado en la RMF las técnicas avanzadas como el tensor de difusión (DTI) y las imágenes de espectroscopia por resonancia magnética (MRS); sin embargo, su aplicación es limitada por los tiempos prolongados de adquisición y la necesidad de software no comerciales especializados ${ }^{12}$.

No se ha encontrado evidencia de efectos adversos en el feto humano con el uso de medios de contraste basados en gadolinio, pero su uso durante el embarazo no ha recibido aprobación. La FDA lo clasifica como un agente de clase $C$, lo que significa que hay evidencia de efectos adversos en estudios en animales, sin estudios adecuados en seres humanos. El Colegio Americano de Radiología (ACR) considera que el gadolinio puede usarse en el embarazo, siempre y cuando su beneficio sea mayor que el riesgo. En este caso se recomiendan los agentes macrocíclicos en la menor dosis posible ${ }^{13}$.

Los estudios de RMF casi siempre se adquieren en equipos $1.5 \mathrm{~T}$ mediante una antena de cuerpo. El uso de $3.0 \mathrm{~T}$ también es aceptable, aunque requiere un software más avanzado para evitar el efecto B1 en las imágenes. Se prepara a las pacientes previamente para reducir al máximo la incomodidad y los artefactos por movimiento. Es necesario un ayuno mínimo de cuatro horas y se ingresa al equipo inmediatamente después de vaciar el contenido vesical. Con posterioridad, la paciente se coloca en el equipo en decúbito supino y, en caso de no tolerar esa posición, en decúbito lateral izquierdo. Se coloca una antena de superficie sobre el abdomen de la paciente.

\section{MATERIAL Y MÉTODOS}

Se incluyó a pacientes con estudios de RMF realizados en el Hospital Ángeles Lomas (Huixquilucan, Estado de México) entre enero de 2005 y diciembre de 2019. Los criterios de inclusión fueron los siguientes: a) pacientes con RMF previa en el segundo y tercer trimestres del embarazo; b) pacientes con US fetal con sospecha o diagnóstico previo de afección, así como pacientes con ultrasonido 
normal con factores de riesgo, como antecedentes familiares o enfermedad existente relacionada con malformaciones (p. ej., búsqueda de lesiones tuberosas o nódulos subependimarios en pacientes con rabdomioma cardíaco o, en embarazos gemelares, afectación de uno de los fetos con una malformación u óbito); c) pacientes que contaban con imágenes y estudios tanto de RMF como de US en las bases de datos. Se excluyó a aquellos que no satisfacían los criterios de inclusión.

Se dividió a los participantes en dos grupos: pacientes con 18 a 27 SDG y pacientes con 28 a 36 SDG. Se clasificaron de acuerdo con la región anatómica a la que correspondía la anomalía de la siguiente manera: a) afección del sistema nervioso central; b) afección de cabeza y cuello; c) afección torácica; y d) afección de abdomen y pelvis.

Todos se clasificaron de acuerdo con el diagnóstico establecido por US y por RMF y luego se compararon los diagnósticos emitidos en ambos estudios y se agruparon en cuatro categorías para determinar si la RMF aportaba o no información adicional, como se muestra en la Tabla 1.

Especialistas en ginecología y obstetricia con subespecialidad en medicina maternofetal en los departamentos de medicina maternofetal del Hospital Ángeles Lomas y el Instituto Nacional de Perinatología, todos con más de 10 años de experiencia y certificados por el Consejo Mexicano de Ginecología y Obstetricia en Medicina Materno Fetal, realizaron los estudios ultrasonográficos. Se utilizaron equipos de ultrasonido marca General Electric, modelo Voluson E6, de acuerdo con los protocolos y guías de la Sociedad Internacional de
Tabla 1. Categorías para determinar si la RMF aporta información adicional al US

No aporta información adicional

- Concordancia diagnóstica: el estudio de RM no suministró nuevos datos diagnósticos y corroboró los hallazgos ultrasonográficos.

Sí aporta información adicional

- Cambio de diagnóstico: el estudio de RM descartó el diagnóstico ultrasonográfico y aportó nueva información.

- Aporta información adicional: el estudio de RM confirmó los hallazgos ultrasonográficos y aportó información adicional.

- Descarte de anormalidades: el estudio de RM descartó el diagnóstico ultrasonográfico, sin aportar información adicional.

Ultrasonido, Obstetricia y Ginecología (ISUOG), en estrecha comunicación con los médicos tratantes de las pacientes.

Los individuos referidos del servicio de medicina maternofetal con sospecha clínica o diagnóstico ultrasonográfico de afección se sometieron a estudio de RMF mediante dos unidades de resonancia magnética de 1.5 Tesla (SIEMENS Aera y Symphony), con secuencias HASTE (half-Fourier acquisition single-shot turbo spin echo) T1 GRE y difusión. La duración aproximada de los estudios fue de 30 minutos y los interpretó un radiólogo especialista en resonancia magnética con más de 10 años de experiencia, certificado por el Consejo Mexicano de Radiología e Imagen (CMRI).

\section{RESULTADOS}

De los 298 pacientes objeto de RMF, se excluyó a aquellos que no reunían los criterios de inclusión, de tal modo que se integró una muestra de 146 pacientes en total. 
La edad materna promedio fue de $30 \pm 6.8$ años, la edad gestacional promedio fue de 30 \pm 7.7 SDG. De los 146 pacientes, 39 se realizaron entre las semanas 18 y 27 de gestación y 107 entre las semanas 28 y 36. Los diagnósticos ultrasonográficos por los que se solicitó el estudio de RMF se enlistan en la Tabla 2.

La mayoría de los pacientes (69\%) se refirió por enfermedad del SNC, seguida por diagnósticos de afección torácica (11\%), alteración abdominopélvica (10\%) y trastornos de cabeza y cuello (10\%) (Fig. 1).

La RMF confirmó los hallazgos de US en 44\% de los pacientes y suministró información adicional en $56 \%$ de los casos. De los casos ( $n=82)$ en los que la RMF añadió información, en la mayor parte $(n=48)$ la $R M F$ proporcionó nuevos hallazgos al diagnóstico ultrasonográfico; en otros pacientes $(n=31)$ se cambió el diagnóstico de US, con determinación de un nuevo diagnóstico, y en unos cuantos $(n=3)$ descartó alteraciones y se estableció un estudio normal (Fig. 2).

No hubo diferencias en el aporte de la RM después de la semana 28 de gestación al comparar a los pacientes valorados entre las semanas 18 y 27 de gestación (Tabla 3 y Fig. 3).

En la enfermedad del SNC, la ventriculomegalia fue el diagnóstico de referencia más frecuente $(\mathrm{n}=64)$, en el cual la RMF añadió información adicional en el $60 \%$ de las veces. Algunos de los hallazgos adicionales incluyeron disgenesias del cuerpo calloso, hemorragias de la matriz germinal y esquizencefalias relacionadas con la ventriculomegalia (Fig. 4). Los otros diagnósticos de afección del SNC detectados por US en las que la RMF
TABLA 2. Diagnósticos ultrasonográficos por los cuales se solicitó estudio de RMF

\begin{tabular}{|c|c|c|c|}
\hline $\begin{array}{l}\text { Región } \\
\text { anatómica }\end{array}$ & $\begin{array}{l}\text { Diagnóstico de US } \\
\text { por el cual se } \\
\text { solicitó RMF }\end{array}$ & $\begin{array}{l}\text { No. } \\
\text { casos }\end{array}$ & $\begin{array}{l}\text { RMF aportó } \\
\text { información } \\
\text { adicional } \\
\text { No. } \\
\text { casos (\%) }\end{array}$ \\
\hline \multirow[t]{2}{*}{$\begin{array}{l}\text { Sistema } \\
\text { nervioso } \\
\text { central }\end{array}$} & $\begin{array}{l}\text { Ventriculomegalia } \\
\text { Defecto del tubo } \\
\text { neural } \\
\text { Lesiones en fosa } \\
\text { posterior } \\
\text { Anormalidades del } \\
\text { cuerpo calloso } \\
\text { Defectos de la línea } \\
\text { media } \\
\text { Defecto de migración } \\
\text { neuronal } \\
\text { Encéfalo normal* } \\
\text { Lesión hemorrágica }\end{array}$ & $\begin{array}{l}64 \\
22 \\
16 \\
11 \\
10 \\
8 \\
5 \\
3\end{array}$ & $\begin{array}{l}38(60 \%) \\
10(45 \%) \\
11(68 \%) \\
9(82 \%) \\
6(60 \%) \\
4(50 \%) \\
3(60 \%) \\
1(33 \%)\end{array}$ \\
\hline & \multicolumn{3}{|c|}{$\begin{array}{l}\text { * Referidos para descartar lesiones en SNC por } \\
\text { rabdomioma cardíaco }\end{array}$} \\
\hline $\begin{array}{l}\text { Cabeza y } \\
\text { cuello }\end{array}$ & $\begin{array}{l}\text { Linfangioma cervical } \\
\text { Épulis }\end{array}$ & $\begin{array}{l}2 \\
1\end{array}$ & $\begin{array}{l}2(100 \%) \\
1(100 \%)\end{array}$ \\
\hline Tórax & $\begin{array}{l}\text { Malformación } \\
\text { congénita de la vía } \\
\text { aérea } \\
\text { Hernia diafragmática } \\
\text { derecha } \\
\text { Masa pulmonar } \\
\text { quística } \\
\text { Desplazamiento de } \\
\text { silueta cardíaca } \\
\text { Masa torácica }\end{array}$ & $\begin{array}{l}1 \\
1 \\
1 \\
1\end{array}$ & $\begin{array}{c}0 \\
1(100 \%) \\
1(100 \%) \\
1(100 \%)\end{array}$ \\
\hline $\begin{array}{l}\text { Abdomen y } \\
\text { pelvis }\end{array}$ & $\begin{array}{l}\text { Poliquistosis renal } \\
\text { Pentalogía de Cantrell } \\
\text { Hidronefrosis } \\
\text { Neuroblastoma } \\
\text { Agenesia renal } \\
\text { Quiste intraabdominal } \\
\text { Quiste hepático } \\
\text { Tumor intraabdominal }\end{array}$ & $\begin{array}{l}1 \\
1 \\
1 \\
1 \\
1 \\
1 \\
1 \\
1\end{array}$ & $\begin{array}{c}0 \\
0 \\
0 \\
1(100 \%) \\
1(100 \%) \\
1(100 \%) \\
1(100 \%) \\
1(100 \%)\end{array}$ \\
\hline
\end{tabular}

proporcionó información adicional fueron alteraciones del cuerpo calloso, alteración de la fosa posterior y defectos del tubo neural. El diagnóstico final establecido por RMF fue aislado en algunas ocasiones y distinto al observado al US; en otros casos incluía el diagnóstico determinado en el ultrasonido pero se 


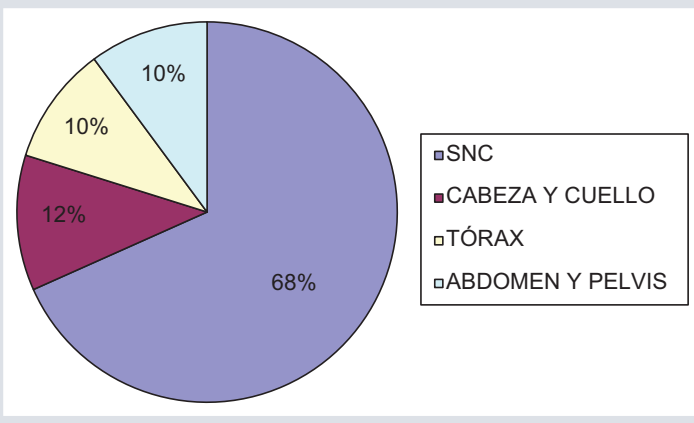

Figura 1. Afección por regiones anatómicas de los estudios de RMF.

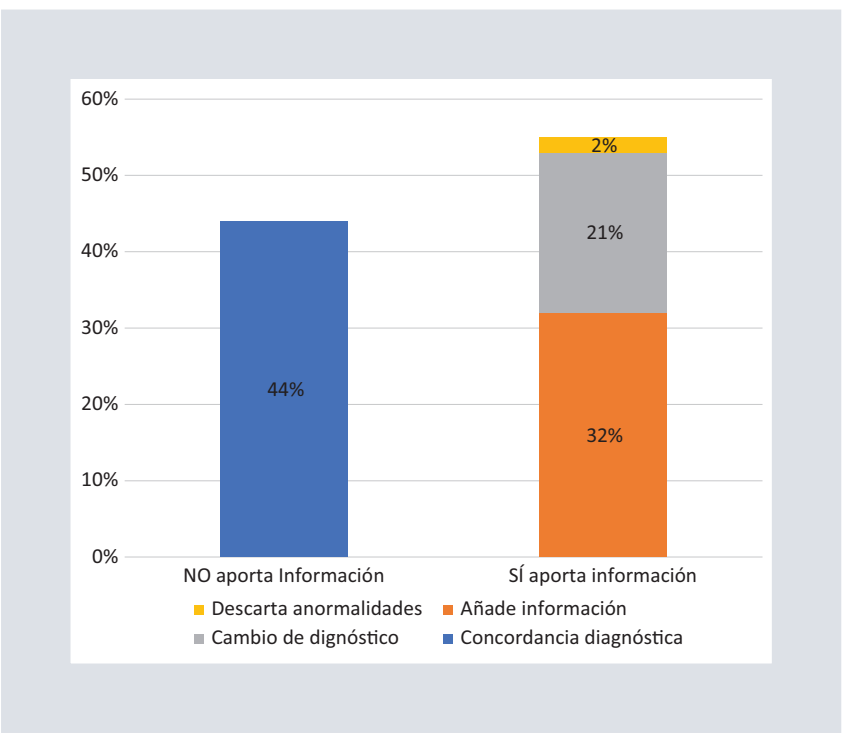

Figura 2. Aportación de la RMF al diagnóstico por US.

vinculaba con otras anomalías no sospechadas por ese método diagnóstico (Tabla 4).

En la enfermedad de cabeza y cuello, los diagnósticos de referencia fueron linfangioma $(n=2)$ y épulis $(n=1)$; en estos casos, la RMF permitió determinar con mayor precisión las dimensiones de la lesión y su relación con las estructuras contiguas y establecer si había compromiso de la vía aérea, un dato de gran utilidad para determinar la necesidad de un tratamiento ex utero intraparto (EXIT). De
Tabla 3. Pacientes divididos por grupos de edad gestacional

\begin{tabular}{|c|c|c|}
\hline SDG & No. de pacientes & $\begin{array}{c}\text { RM aportó información } \\
\text { adicional, n (\%) }\end{array}$ \\
\hline $18-27$ & 39 & $22(56 \%)$ \\
\hline $28-36$ & 107 & $60(56 \%)$ \\
\hline
\end{tabular}

No hubo diferencias significativas entre los grupos, $\mathrm{P}=0.05$.

TABLA 4. Afección del SNC diagnosticada por el estudio de RMF

\begin{tabular}{|l|c|c|c|}
\hline $\begin{array}{l}\text { Afección de SNC } \\
\text { Diagnóstico por } \\
\text { RMF }\end{array}$ & $\begin{array}{c}\text { No. } \\
\text { casos }\end{array}$ & $\begin{array}{c}\text { Afección } \\
\text { aislada }\end{array}$ & $\begin{array}{c}\text { Afección } \\
\text { relacionada } \\
\text { con otras } \\
\text { anormalidades }\end{array}$ \\
\hline $\begin{array}{l}\text { Ventriculomegalia } \\
\text { Lesiones en fosa } \\
\text { posterior }\end{array}$ & 23 & $24(42 \%)$ & $33(58 \%)$ \\
\hline $\begin{array}{l}\text { Anomalías del } \\
\text { cuerpo calloso }\end{array}$ & 23 & $11(47 \%)$ & $19(82 \%)$ \\
\hline $\begin{array}{l}\text { Defecto del tubo } \\
\text { neural }\end{array}$ & 21 & $15(72 \%)$ & $6(28 \%)$ \\
\hline $\begin{array}{l}\text { Defectos de la línea } \\
\text { media }\end{array}$ & 14 & $2(14 \%)$ & $12(52 \%)$ \\
\hline $\begin{array}{l}\text { Defecto de } \\
\text { migración neuronal }\end{array}$ & 21 & $10(48 \%)$ & $11(52 \%)$ \\
\hline \begin{tabular}{l} 
Lesión hemorrágica \\
\hline
\end{tabular} & 7 & $5(72 \%)$ & $2(28 \%)$ \\
\hline
\end{tabular}

esta manera, la RM confirmó el diagnóstico del US y aportó información más precisa (Fig. 5).

En la afección de tórax, el diagnóstico de referencia más común fue la malformación congénita de la vía aérea pulmonar $(n=3)$ y en un 30\% de los casos, la RMF suministró información adicional (Fig. 6), incluidos la medición del volumen de la lesión y el volumen del pulmón contralateral. Uno de estos casos representó una lesión híbrida (malformación congénita de la vía aérea pulmonar y secuestro pulmonar). Además, se detectaron otras 


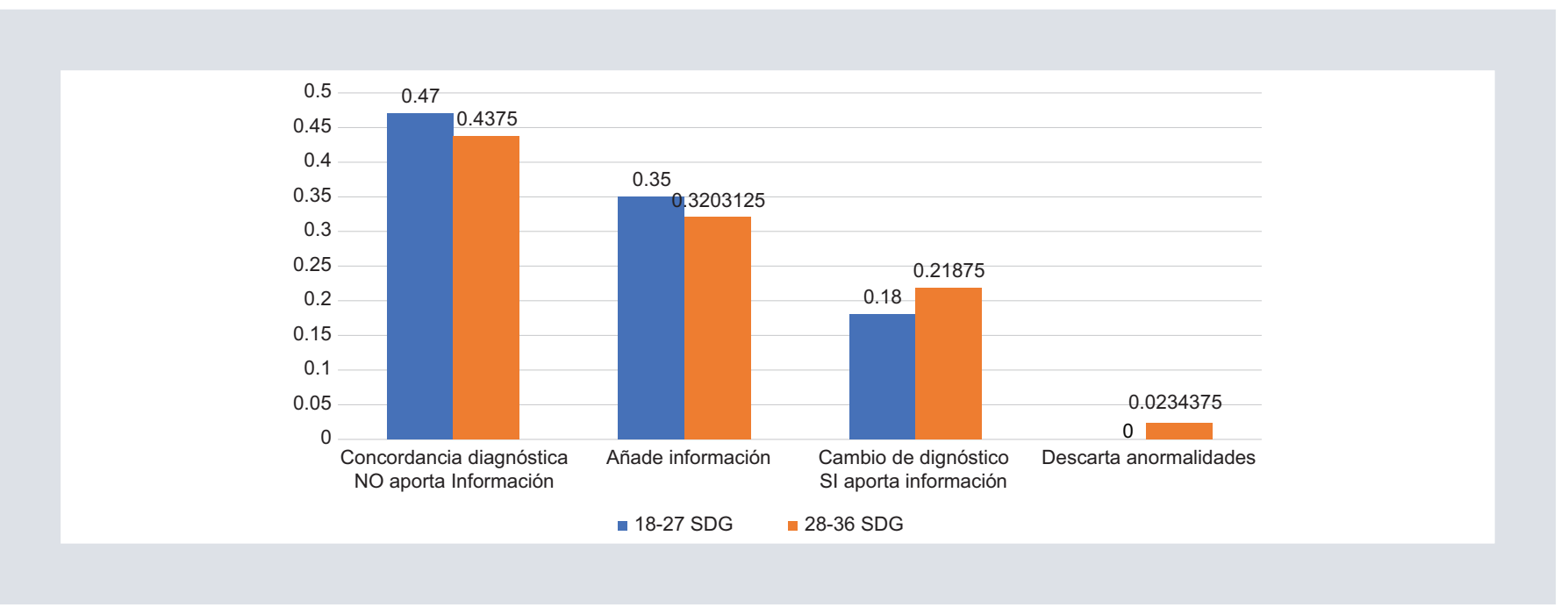

Figura 3. Aportación de la RMF al diagnóstico por US en el segundo y el tercer trimestre de gestación.

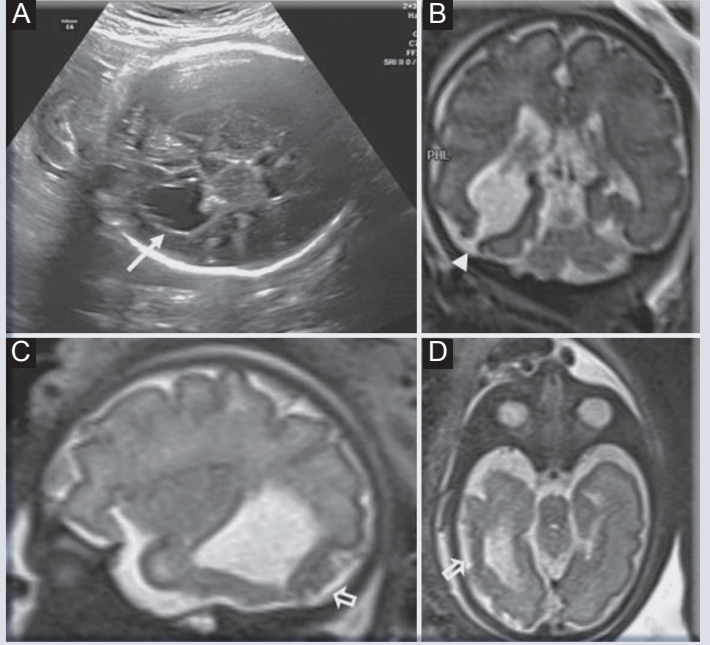

Figura 4. Paciente de 44 años de edad con 31 SDG. A: Se observa un corte axial de US del encéfalo con colpocefalia unilateral (flecha). B-D: En las imágenes de RM se identifica esquizencefalia de labio abierto (punta de flecha), con dilatación del asta occipital derecha, además de polimicrogiria (flecha abierta).

dos malformaciones congénitas de la vía aérea pulmonar por RMF cuyo diagnóstico por US había sido diferente.

De los casos con anomalía abdominopélvica, en el $62 \%$ de los casos la RMF añadió información adicional. Algunos ejemplos fueron la confirmación de un riñón ectópico mediante la secuencia DWI (cuando existía sospecha de agenesia renal por US), la caracterización de un quiste pélvico como una malformación de la cloaca y la diferenciación de un neuroblastoma de un secuestro extralobar (Fig. 7). En esta región anatómica no hubo un diagnóstico en el que predominara la contribución de la RMF.

\section{DISCUSIÓN}

La RMF tiene dos funciones principales en el diagnóstico de afección prenatal. El primero es confirmar el diagnóstico ultrasonográfico, lo que proporciona mayor seguridad al médico y los padres. El segundo es agregar información relevante, ya sea al suministrar más hallazgos al diagnóstico inicial, cambiarlo o incluso descartarlo.

En cualquiera de los dos casos es posible conocer con mayor certeza el pronóstico de 


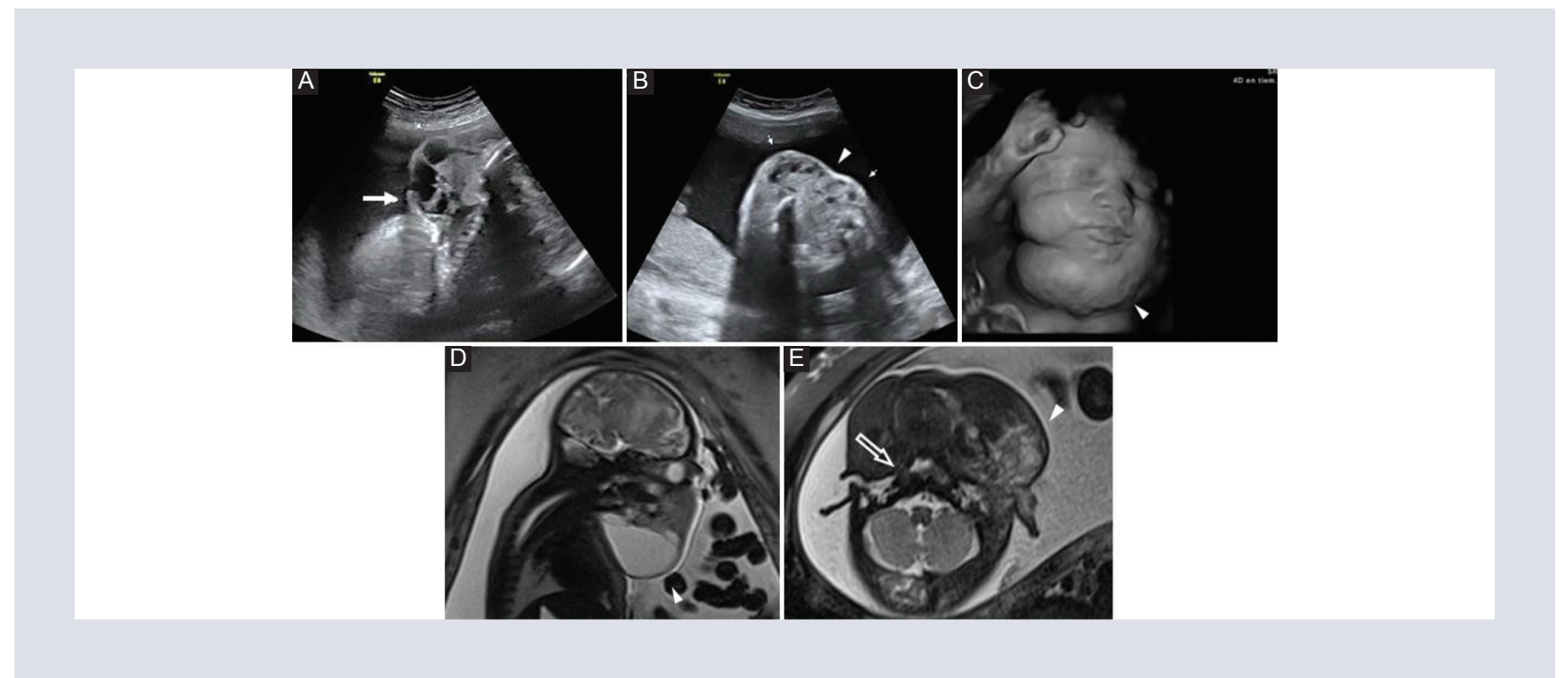

Figura 5. Paciente de 35 años de edad con 30 SDG. A: imagen axial sagital de la lesión. B: reconstrucción tridimensional. C: US de una lesión multiquística en el cuello consistente con linfangioma cervical; en este estudio no fue posible valorar la vía aérea. D-E: las imágenes de RM confirman el aspecto multiquístico de la lesión (punta de flecha). Se puede valorar la vía aérea a nivel de la nasofaringe, la cual se encuentra permeable (flecha abierta).

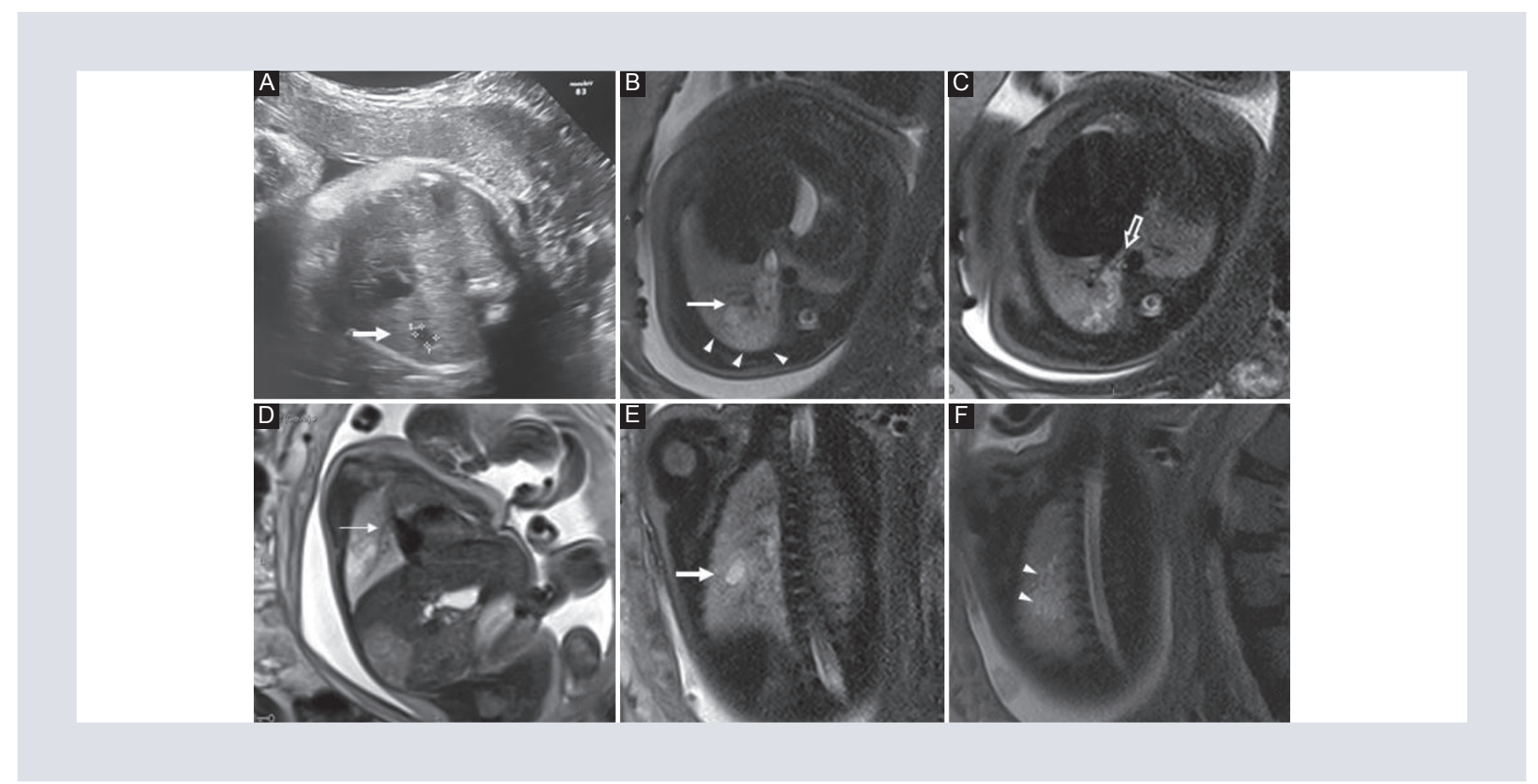

FIgura 6. Paciente de 39 años de edad con 31 SDG. A: se identifica en la imagen axial de US del tórax una lesión de aspecto quístico (flecha sólida). B-E: en las imágenes axiales de RM se reconoce la lesión con una porción quística (flecha en las imágenes) y una porción sólida (cabezas de flecha en las imágenes. B-F: de localización posterior y medial. C: se delinea una arteria nutricia (flecha hueca) que emerge de la aorta torácica. D: en la imagen sagital se señala (flecha delgada) una vena que drena a la aurícula en relación con un vaso de drenaje. Estos hallazgos corresponden a malformación congénita de la vía pulmonar relacionada con secuestro pulmonar. 

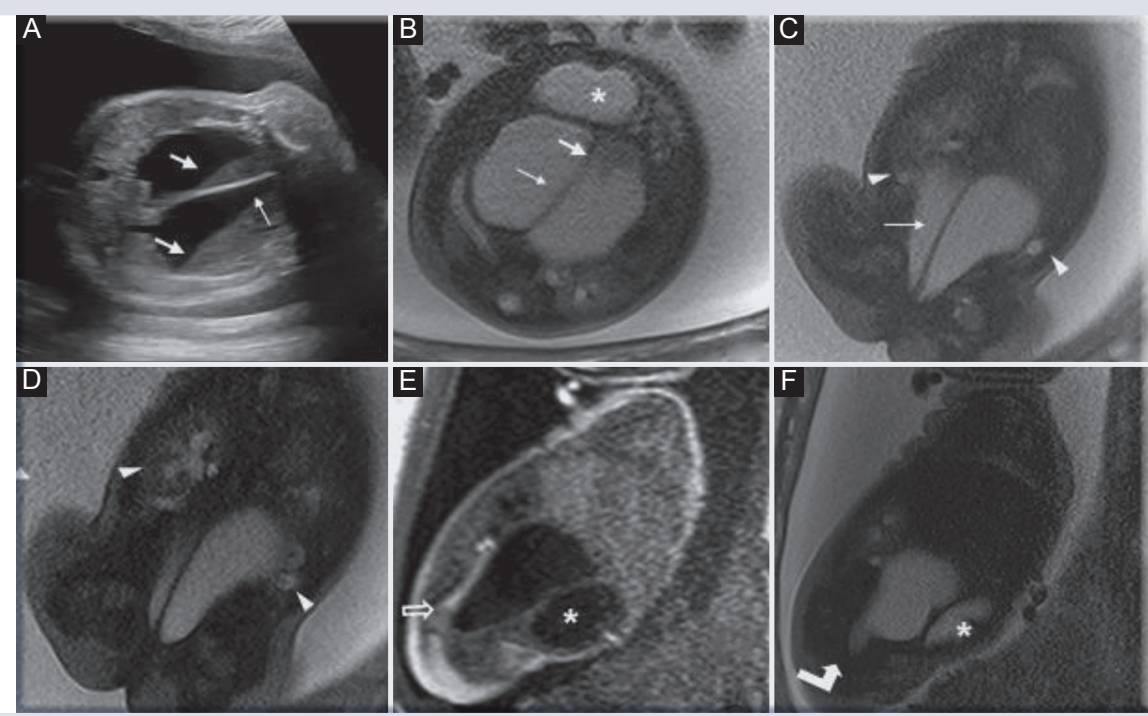

Figura 7. Paciente de 36 años de edad. A: en el ultrasonido realizado a las 34 SDG se detectó polihidramnios y una lesión quística en el abdomen con tabique grueso (flecha delgada) y niveles líquido-líquido (flechas gruesas). B: en las imágenes de RM se diagnosticó malformación de la cloaca. C-D: en las imágenes axial y coronales se observa la imagen quística que corresponde a la vagina dilatada septada (flecha delgada) con detritus en su interior (flecha gruesa). También se observa dilatación de los uréteres y sistemas colectores (cabezas de flechas). E-F: en las imágenes sagitales se observa la vejiga anterior a la lesión (asterisco) y la vagina distendida que termina en embudo (flecha angulada) al mismo nivel del recto (hiperintenso en la imagen ponderada en T1 por la presencia de meconio), el cual termina antes de llegar al perineo. El diagnóstico fue una malformación de la cloaca (disgenesia cloacal).

los pacientes y ayudar a tomar decisiones preventivas y terapéuticas, lo que produce un efecto positivo en el tratamiento integral del feto y el recién nacido.

La mayor parte de los casos en los que se utiliza la RMF se relaciona con afectación del SNC, en la cual la RMF permite realizar una valoración más detallada de la anatomía y hace posible la caracterización tisular de las lesiones. Sin embargo, su uso no es exclusivo de esta región anatómica, ya que en la enfermedad de tórax, abdomen y pelvis también proporciona información adicional. Si bien en los casos de cabeza y cuello incluidos en este estudio los hallazgos encontrados en la RMF sólo confirmaron los identificados en el US (concordancia de hallazgos), la RMF es muy útil, sobre todo para valorar la permeabilidad de la vía aérea y ello permite planear una intervención quirúrgica prenatal o anticipar la protección de ésta durante el nacimiento (procedimiento EXIT).

Es importante mencionar que la RMF también tuvo un papel importante al agregar información en casos de oligohidramnios, en el cual no se podían delinear los riñones por US y era necesario descartar una agenesia renal. Esto último fue posible gracias a la aplicación de la secuencia de difusión (Fig. 8).

Una de las limitaciones más importantes fue que de los 298 estudios efectuados entre 2005 y 2019 sólo se dispuso del informe y las 

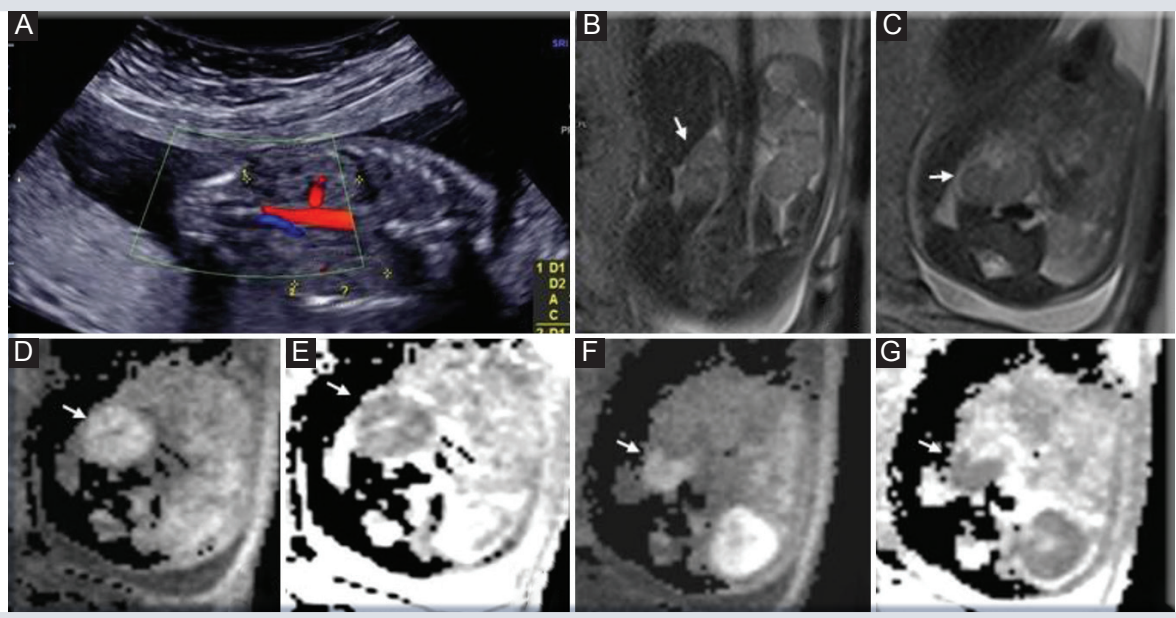

Figura 8. Paciente de 27 años de edad. A: en el ultrasonido realizado a las 19 SDG no se observa la arteria renal derecha ni el riñón ipsolateral. B-D: imágenes de la RM realizada a las 27 SDG. B-C: se identifica en las imágenes T2 el riñón derecho rotado, con el hilio hacia delante. D-G: las imágenes de difusión confirman que la imagen corresponde a tejido renal con restricción a la difusión (flechas blancas).

imágenes de ultrasonido de 146 pacientes, por lo que fue necesario excluir a más de la mitad de los pacientes.

Para establecer valores de sensibilidad y especificidad para cada enfermedad es preciso confirmar el diagnóstico con estudios de imagen o seguimiento clínico posnatal. En este estudio se tenía tan sólo confirmación posnatal en 11 de los pacientes en la base de datos y por ello no fue posible calcularlos.

Éste es un problema común en las publicaciones médicas mundiales debido a la dificultad para darle seguimiento a estos pacientes. En este punto es posible mejorar las investigaciones subsecuentes.

Estos resultados son similares a los obtenidos en otros estudios a gran escala, como el protocolo multicéntrico MERIDIAN en el cual Griffiths, et al. señalaron que la RM suministró información adicional en un 49\% de los casos y cambió la información acerca del pronóstico en un $20 \%{ }^{14}$.

El propósito de la RMF debe ser complementar la información obtenida con el ultrasonido, ya sea al confirmar los hallazgos o proporcionar información adicional; sin embargo, no debe usarse como la herramienta primaria de tamizaje prenatal ${ }^{15,16}$.

\section{CONCLUSIÓN}

La RMF constituye una herramienta valiosa para la valoración de afección prenatal, ya que en el 56\% de los casos proporciona información adicional a la obtenida en los estudios ecográficos y en el 44\% confirma los hallazgos obtenidos con el ultrasonido. 
Es importante idear medidas para mejorar el seguimiento posnatal de los recién nacidos y establecer la sensibilidad y especificidad de este método de imagen.

\section{AGRADECIMIENTOS}

Los autores agradecen a los técnicos radiólogos y residentes, sin los que no hubiera sido posible llevar a cabo los estudios de RM fetal.

\section{FINANCIAMIENTO}

Esta investigación no ha recibido beca específica de agencias de los sectores público, comercial o sin ánimo de lucro.

\section{CONFLICTO DE INTERESES}

Los autores declaran no tener ningún conflicto de intereses.

\section{RESPONSABILIDADES ÉTICAS}

Protección de personas y animales. Los autores declaran que para esta investigación no se han realizado experimentos en seres humanos ni en animales.

Confidencialidad de los datos. Los autores declaran que han seguido los protocolos de su centro de trabajo sobre la publicación de datos de pacientes.
Derecho a la privacidad y consentimiento informado. Los autores declaran que en este artículo no aparecen datos de pacientes.

\section{BIBLIOGRAFÍA}

1. Kamishima T, Nishihori T, Mitchell DG, Nambu T, Fujita N, Miyasaka K. MR imaging of the fetus. Radiologist. 2001;8(5):245-253. doi:10.1097/00042423-200109000-00005

2. AIUM, ACR, ACOG, SRU. AIUM practice parameter for the performance of obstetric ultrasound examinations. AIUM Pract Param. 2013:1-17. doi:10.7863/ultra.32.6.1083

3. Saleem SN. Fetal MRI: an approach to practice: a review. J Adv Res. 2014;5(5):507-523. doi:10.1016/j.jare.2013.06.001

4. Chung JH, Pelayo R, Hatfield TJ, Speir VJ, Wu J, Caughey AB. Limitations of the fetal anatomic survey via ultrasound in the obese obstetrical population. J Matern Neonatal Med. 2012;25(10):1945-1949. doi:10.3109/147670 58.2012.670332

5. Bulas D, Egloff A. Benefits and risks of MRI in pregnancy. Semin Perinatol. 2013;37(5):301-304. doi:10.1053/j.semperi.2013.06.005

6. Ray JG, Vermeulen MJ, Bharatha A, Montanera WJ, Park AL. Association between MRI exposure during pregnancy and fetal and childhood outcomes. JAMA - J Am Med Assoc. 2016;316(9):952-961. doi:10.1001/jama.2016.12126

7. Jarvis D, Mooney C, Cohen J. A systematic review and meta-analysis to determine the contribution of MR imaging to the diagnosis of foetal brain abnormalities in utero. Eur Radiol. 2017;27(6):2367-2380. doi:10.1007/ s00330-016-4563-4

8. Whitby EH, Paley MNJ, Sprigg A. Comparison of ultrasound and magnetic resonance imaging in 100 singleton pregnancies with suspected brain abnormalities. BJOG An Int J Obstet Gynaecol. 2004;111(8):784-792. doi:10.1111/j.1471-0528.2004.00149.x

9. College A. Acr - Spr Practice Guideline for the Safe and Optimal Performance of Fetal Magnetic Resonance Imaging (MRI). 2010;1076 (revised 2008):1-12.

10. ISUOG Practice Guidelines: performance of fetal magnetic resonance imaging. Ultrasound Obstet Gynecol 2017;49:671-680. doi: 10.1002/uog.17412

11. Miller E, Ben-Sira L, Constantini S, Beni-Adani L. Impact of prenatal magnetic resonance imaging on postnatal neurosurgical treatment. J Neurosurg. 2006;105(3 Suppl):203-209. doi:10.3171/ped.2006.105.3.203

12. Kasprian G, Brugger PC, Weber M. In utero tractography of fetal white matter development. Neuroimage. 2008;43(2):213-224. wwdoi:10.1016/j. neuroimage.2008.07.026

13. Mervak BM, Altun E, McGinty KA, Hyslop WB, Smelka RC, Burke LM MRI in pregnancy: indications and practical considerations. Magn Reson Imaging 2019;49(3):621-631.

14. Griffiths PD, Bradburn M, Campbell MJ, Cooper CL, Jarvis D, Kilby MD, et al. Use of MRI in the diagnosis of fetal brain abnormalities in utero (MERIDIAN): a multicentre, prospective cohort study; Lancet. 2017;389:53846. Doi 10.1016/S0140-6736(16)31723-8

15. Eisenberg VH, Schenker JJ. The moral aspects of prenatal diagnosis. Eur J Obstet Gynecol Reprod Biol. 1997;72(1):35-45. doi:10.1016/ S0301-2115(96)02667-X

16. Tercanli S, Prüfer F. Fetal neurosonogaphy: ultrasound and magnetic resonance imaging in competition. Ultraschall der Medizin - Eur J Ultrasound. 2016;37(06):555-557. doi:10.1055/s-0042-117142 